\title{
Comparison of Histopathologic Coronary Lesions Obtained from Directional Atherectomy in Stable Angina Versus Acute Coronary Syndromes
}

Uri Rosenschein, MD, Stephen G. Ellis, MD, Christian C. Haudenschild, MD, Steven J. Yakubov, MD, David W. M. Muller, MBBS, Ronald J. Dick, MBBS, and Eric J. Topol, MD

$\mathrm{T}$ he transition of coronary lesions from the stable to unstable state is the pathophysiologic mechanism underlying myocardial infarction and unstable angina pectoris. Angiographic, angioscopic and postmortem pathologic studies suggest that this transition is mainly due to atherosclerotic plaque fissuring and associated thrombus formation. 1,2 The present study examines the histopathologic characteristics of the "culprit lesion" obtained during directional coronary atherectomy of patients with acute coronary syndromes. Directional atherectomy provides a unique opportunity for studying the composition of unstable lesions in living symptomatic patients.

Case histories of consecutive patients referred to the University of Michigan Medical Center for directional coronary atherectomy after May 1, 1989 were analyzed. All patients selected for inclusion in this study had angina, objective evidence of myocardial ischemia and cineangiograms showing $\geq 1$ lesion with $>50 \%$ diameter stenosis of an epicardial coronary artery. The unstable group comprised patients who had experienced ischemic pain at rest accompanied by transient $S T-T$ changes on the electrocardiogram, or acute myocardial infarction during the 2-week period preceding directional atherectomy. The stable group comprised patients who had not had ischemic pain at rest, progressive angina, recent-onset angina or acute myocardial infarction during the 3-month period preceding directional atherectomy.

Directional atherectomy was performed as described previously. ${ }^{3}$ The atherectomy device (Devices for Vascular Intervention Inc., Redwood City, California) consists of a cylindrical metal housing, with a window opening an eccentric balloon on the opposite side of the window, and a cylindrical, rotating, cutting blade inside the housing. The device was advanced to the coronary stenosis over a 0.014-inch guide wire through a special 11 or $9.5 \mathrm{Fr}$ guiding catheter (Devices for Vascular Intervention Inc.). Each lesion was crossed with the device (5 to $7 F r$ ), and a series of cuttings were made under fluoroscopic guidance; then, the atherectomy device was removed, and the tissue specimens were collected.

Histopathologic analysis of the atherectomy specimen was performed as previously described. ${ }^{4}$ Briefly, immediately after removal from the atherectomy device,

From the Cleveland Clinic Foundation, Desk F25, One Clinic Center, 9500 Euclid Avenue, Cleveland, Ohio 44195; the University of Michigan Medical Center, Ann Arbor, Michigan; and Boston University, Boston, Massachusetts. Dr. Rosenschein's current address is: Department of Cardiology. Tel Aviv Medical Center, 6 Weisman Street, Tel Aviv 64239, Israel. Manuscript received October 8, 1992; revised manuscript received and accepted July 12, 1993. the specimens were fixed, processed routinely and stained with either hematoxylin-eosin or Verhoeff-Van Giesson elastic tissue stain.

The histologic sections were analyzed at a remote pathology core laboratory by an experienced cardiac pathologist $(\mathrm{CCH})$ unaware of the clinical details. The slides were positioned on the stage of a projection light microscope, and the image was projected onto a digitizing tablet (MOP, Carl Zeiss Instr, Germany). Each different tissue component was outlined, measured $\left(\mu^{2}\right)$ and expressed as a percentage of the total atherosclerotic plaque area.

The different tissue components were defined as follows: Media was characterized by parallel arrangement of smooth muscle cells, located between the elastic lamina. Adventitia was characterized by thick bundles of dense collagen with few interspersed elastin fibers, located exterior to the external elastic lamina.

Atherosclerotic lesion was defined as containing $\geq 1$ of the following components: Atheromatous tissue was defined by extracellular cholesterol crystals and foam cells. Atheromatous tissue often contained necrotic regions and amorphous extracellular matrix. Fibrosclerotic tissue was characterized by heavy collagen and elastin fiber matrix with scant cellularity. Fibrocellular tissue was defined when the fibrous matrix contained abundant cellularity. The cells consisted of macrophages and spindle shaped cells resembling smooth muscle cells, myofibroblasts and fibroblasts. Organized thrombus was defined when it contained loose cellular tissue in myxomatous stroma with fibrin remnants, occasional

\begin{tabular}{|lcc|}
\hline TABLE I Patient Characteristics & & \\
\hline & $\begin{array}{c}\text { Unstable } \\
(n=44)\end{array}$ & $\begin{array}{c}\text { Stable } \\
(n=55)\end{array}$ \\
\hline Clinical & & \\
Age (years) & $60 \pm 12$ & $58 \pm 12$ \\
Men & $29(66 \%)$ & $41(74 \%)$ \\
Positive family history & $23(52 \%)$ & $37(68 \%)$ \\
Current smoking & $21(48 \%)$ & $26(47 \%)$ \\
Hyperchotesterolemia & $25(57 \%)$ & $37(68 \%)$ \\
Systemic hypertension & $15(34 \%)$ & $25(45 \%)$ \\
Insulin-dependent diabetes mellitus & $4(9 \%)$ & $2(3 \%)$ \\
History of PTCA & $13(29 \%)$ & $12(22 \%)$ \\
History of MI & $27(61 \%)$ & $20(36 \%)$ \\
Angiographic & & \\
Severity of culprit lesion & $74 \pm 13$ & $78 \pm 12$ \\
(\% stenosis) & & \\
1-vessel disease & $27(61 \%)$ & $28(53 \%)$ \\
2-vessel disease & $9(20 \%)$ & $15(27 \%)$ \\
3-vessel disease & $11(25 \%)$ & $11(20 \%)$ \\
\hline Nodifferences were significant $(p<0.05)$ between patients with unstable and stable \\
angina, except history of myocardial infarction (MI) (p -0.02$).$
\end{tabular}


red blood cells and ingrowing capillaries. Fresh thrombus was characterized and distinguished from thrombus formed during the procedure by its layered organization, aggregates of platelets, fibrin and erythrocytes. When it occupied $\geq 3000 \mu^{2}$, it was coded as large thrombus.

The frequency of the clinical characteristics, and the histologic evidence of large fresh thrombi were compared in the unstable and stable groups by analyzing contingency table data with the use of chi-square analysis. An unpaired Student's t test was used to compare the area of each histologic component in the 2 groups. Data were expressed as mean $\pm 1 S D$. A $p$ value $<0.05$ was considered significant.

One hundred four lesions from 99 patients were studied. The unstable and stable groups were comparable in their clinical and demographic features, except, as expected, for history of acute myocardial infarction, which was more frequent in the unstable group (Table I).

The unstable and stable groups had a similar extent of coronary artery disease (45 and $47 \%$ multivessel disease, respectively; $p=N S$ ), and severity of the culprit lesions $(74 \pm 13 \%$ and $78 \pm 12 \%$ stenosis, respectively; $p=N S$ ).

The composition of the excised coronary lesion specimens was mainly fibrous tissue ( $75 \pm 25 \%$ vs 76 $\pm 23 \%$ area, $p=N S)$. However, lesions excised from the unstable group had a higher frequency of large thrombi $\left(\geq 3000 \mu^{2}\right)$ (44 vs 17\%; $p=0.02$ ) (Figure 1), and a higher degree of cellularity, expressed as a larg. er area of fibrocellular component ( $40 \pm 28 \%$ vs $29 \pm$ $23 \%$ area; $p=0.02$ ) and as a smaller area of $f$ brosclerotic component $(35 \pm 22 \%$ vs $48 \pm 25 \%$ area; $p=0.009$ ) (Figure 2).

This is the first study to describe the histopathologic characteristics of coronary lesions in living patients presenting with acute coronary syndrome. Up to the present,

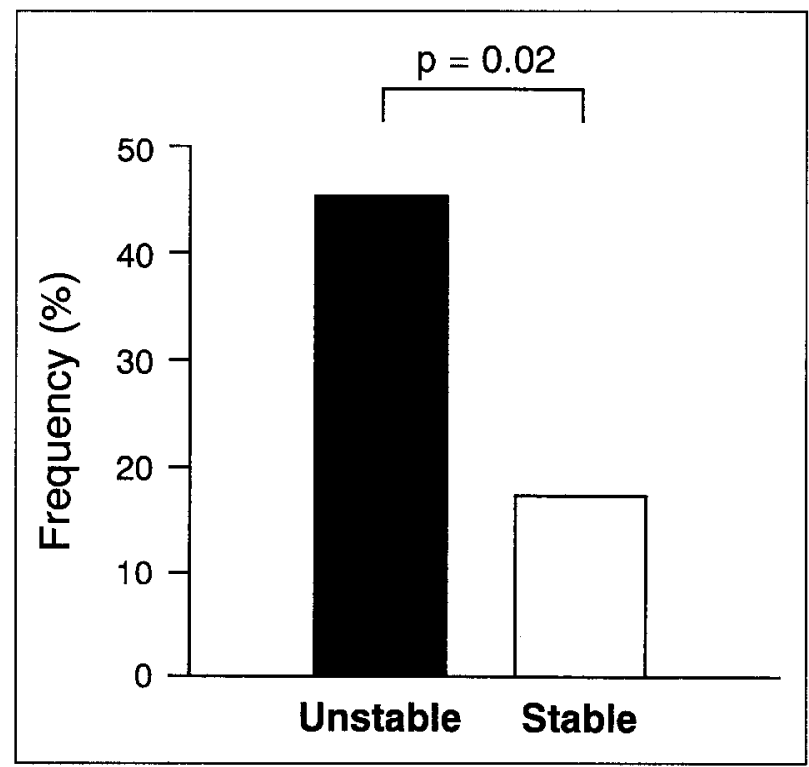

FCIFE 1 Coronary lesions excised from patients with acute coronary syndrome had greater association with large thrombi; 17\% of "stable lesions" were associated with large thrombus. the lesion histopathology in acute coronary syndromes was studied in selected populations of patients who died after acute myocardial infarction or unstable angina. ${ }^{1,2,5}$

Histopathologic analysis showed that coronary lesions, regardless of the clinical presentation, consist primarily of fibrous tissue ( $75 \%$ of the area). Atheromatous material was only a minor component in the composition of atherosclerotic plaques. Similar to the present findings, Kragel et al ${ }^{6}$ have found, in a quantitative histologic analysis of paticnts who dicd of acute myocardial infarction or sudden cardiac death, that fibrous tissue occupied $81 \%$ of the area of unstable plaques.

We found that lesions in patients with acute coronary syndrome are associated with large fresh thrombi. The findings are consistent with the data of other investigators, using angioscopy and pathologic findings, showing an association between unstable lesions and fresh thrombus. $1,2,6,7 \mathrm{We}$ found that a relatively high prevalence of large fresh thrombus accompanied the presence of clinical stability $(17 \%)$. Other investigators have observed this phenomenon while using angioscopy ${ }^{7}$ and in postmortem studies. ${ }^{15,16}$ Thrombus deposition and organization may be an important element in the development of atherosclerotic plaques in humans. ${ }^{8}$ These observations, together with the observed histologic continuum between organizing thrombus and fibrocellular tissue, ${ }^{9}$ suggest that the clinically significant fibrous lesions may represent the progression of early lipid-rich lesions that had undergone repeated, in some cases silent, episodes of thrombosis and thrombus organization. ${ }^{8}$

The data indicate that unstable lesions have a higher degree of cellularity, suggesting that lesions with clinical evidence of recent instability undergo a proliferative phase. Tracy et $\mathrm{a}^{10}$ found a greater degree of cellularity in unstable than in stable plaques in the same patients. Immunohistochemistry of atherosclerotic plaques showed the highest proliferation rate in plaques associated with acute thrombosis. ${ }^{11}$ Several components of the fresh

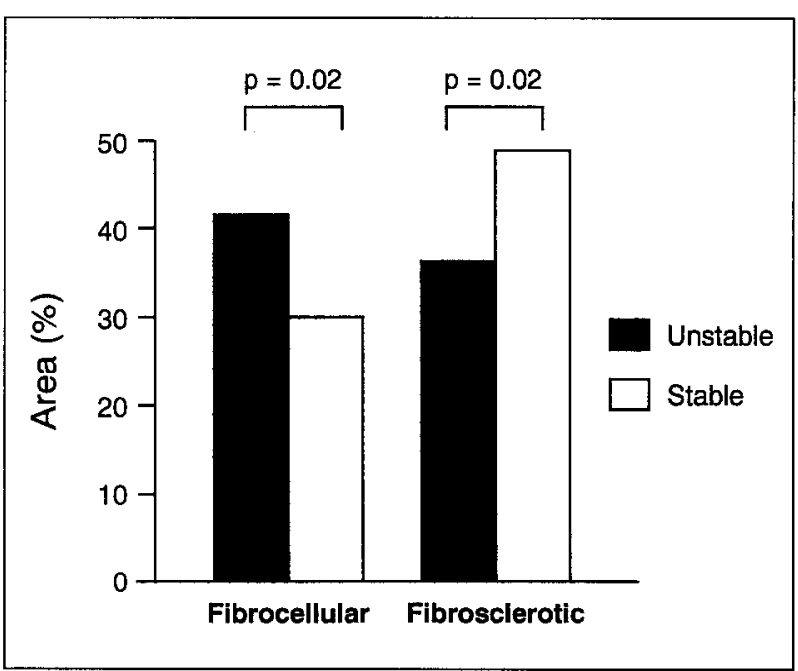

FIGURE 2. Composition of excised coronary lesion specimens, regardless of clinical presentation, was mainly fibrous tissue. In patients with acute coronary syndromes, lesions had greater degree of cellularity manifested as largs or proportion of fibrocellular tissue, and small proportion of fibrosclerotic tissue. 
thrombus may contribute to the proliferative phase. The release of platelet-derived growth factor during platelet activation, ${ }^{12}$ and fibroblast growth factor from the matrix ${ }^{13}$ contributes to the observed expression of growth factors in lesions of patients with unstable angina ${ }^{14}$ and may stimulate smooth muscle proliferation directly. Thus, the combination of large thrombi and a higher degree of cellularity in the unstable lesions in the present study suggests that rupture of the atherosclerotic plaque is followed by thrombus formation. The thrombus initiates the normal healing process by supplying the mitogenic stimulus, as well as the structural matrix, for the proliferation of smooth muscle cells and macrophages. ${ }^{15}$

Excised atherectomy specimens may delineate a bias in atheroma composition. The procedure potentially samples only a portion of the atheroma. Only $52 \%$ of lesion specimens in this series contained arterial wall elements, suggesting that the specimens did not always display full atheroma thickness for histopathologic analyses. Secondary to the device profile and stiffness, certain tissue elements, especially superficial thrombus, may not be excised, but rather pushed downstream when the atherectomy device crosses the lesion; this event may explain some differences in the incidence of thrombus in some angioscopic studies. Atheromatous material may be underestimated in the present study, because special stains for lipids were not used, and lipids may have been lost from the tissue specimen during processing.
1. Falk E. Morphologic features of unstahle atherothrombotic plaques underlying acute coronary syndromes. Am J Cardiol 1989:63:114E-120E

2. Fuster V, Badimon L, Cohen M, Ambrose JA, Badimon JJ, Chesebro J. Insight into the pathogenesis of acute ischemic syndromes. Circulation 1988;77:1213-1220. 3. Kaufmann UP, Garratt KN, Vlietstra RE, Menke KK, Holmes DR. Coronary atherectomy: first 50 patients at the Mayo Clinic. Mayo Clinic Proc 1989;64:747-752. 4. Rosenschein U, Haudenschild CC, Dick RI, Watkins JF, Ellis SG, Yakubov SJ, Topol EJ. Histopathology correlates of coronary lesion angiographic morphology: lessons from a directional atherectomy experience. Coronary Artery Disease 1992;3: 953-961.

5. Davies MJ. A macro and micro view of coronary vascular insult in ischemic heart disease. Circulation 1990;82:38-46

6. Kragel AH, Reddy SG, Wittes JT, Roberts WC. Morphometric analysis of the composition of atherosclerotic plaques in the four major epicardial coronary arterjes in acute myocardial infarction and in sudden coronary death. Circulation 1989;80: $1747-1756$.

7. Forrester JS, Litvack F, Gundfest W, Hickey A. A perspective of coronary disease seen through the arteries of living man. Circulation 1987;75:505-513.

8. Fuster V, Badimon L. Badimon $\mathrm{L}$, Chesebro JH. The pathogenesis of coronary artery disease and the acute coronary syndromes. $N$ Engl J Med 1992;326:242-250.

9. Duguid JB. Thrombosis as a factor in the pathogenesis of coronary atherosclerosis. J Pathol 1946:58:207-212.

10. Tracy RE, Deraney $K$, Kissling G. Characteristics of the plaque under a coronary thrombosis. Virchow's Arch 1985;405:411-427.

11. Gordon D. Reidy MA, Benditt EP. Schwartz SM. Cell proliferation in human coronary arteries. Proc Nat Acad Sci U S A 1990;87:4600-4604.

12. Ross R, Glomset JA. The pathogenesis of atherosclerosis. $N$ Engl $J$ Med 1976: 295:369-377.

13. Lindner V, Reidy MA. Smooth muscle proliferation after vascular injury is inhibited by an antibody against basic FGF (abstr). I Cell Biochem Suppl 1991; $15 \mathrm{C}: 118$.

14. Flugelman MY, Correa R, Yu Z, Keren G, Leon MB, Satler LF, Kent KM Casscells W, Epstein SE. Fibroblast growth factors are expressed in coronary lesions of patients with unstable angina pectoris and those who have post angioplasty restenosis (abstr). J Am Coll Cardiol 1991;17:73A

15. Schwartz RS, Huber KC, Edwards WD, Camnud AR, Vlietstra RE, Holmes $\mathrm{DR}$. Restenosis and the proportional neointimal response to coronary artery injury: results in a porcine model. Circulation 1992;19:267-274.

\title{
Alleviation of Cocaine-Induced Coronary Vasoconstriction with Intravenous Verapamil
}

\author{
Brian H. Negus, MD, John E. Willard, MD, L. David Hillis, MD, D. Brent Glamann, MD, Charles Landau, MD, \\ Richard W. Snyder, MD, and Richard A. Lange, MD
}

\begin{abstract}
Cocaine use has been associated with a number of cardiovascular complications, including angina pectoris, myocardial infarction and sudden cardiac death. ${ }^{1-4}$ Previous studies in humans have shown that cocaine causes epicardial coronary vasoconstriction, which is mediated, at least in part, by $\alpha$-adrenergic stimulation. . $^{5-10}$ Studies in experimental animals have suggested that cocaine may also cause vasoconstriction by altering calcium transport in vascular smooth muscle, ${ }^{11}$ and this can be attenuated by calcium channel blockade. The present study was performed to assess the effect of verapamil, a calcium antagonist, on cocaine-induced coronary vasoconstriction in humans.

Fifteen patients (6 men and 9 women, aged 39 to 65 years) undergoing cardiac catheterization for the evaluation of chest pain were studied. None had a history of prior cocaine use. The protocol was approved by the

From the Department of Internal Medicine (Cardiovascular Division) The University of Texas Southwestern Medical Center, 5323 Harry Hines Boulevard, Dallas, Texas 75235-9047; and the Cardiac Catheterization Laboratory, Parkland Memorial Hospital, Dallas, Texas. Manuscript received April 16, 1993; revised manuscript received and accepted July 6, 1993.
\end{abstract}

Human Subjects Review Committee of the University of Texas Southwestern Medical Center, and all patients gave written informed consent. All participants were studied in the fasting state after receiving 5 to $10 \mathrm{mg}$ of oral diazepam. Antianginal medications were discontinued $>12$ hours before study.

An arterial sheath was placed percutaneously in the femoral artery, through which an $8 F r$ Judkins catheter was advanced to the left coronary artery. Systemic arterial pressure was measured through the catheter, and heart rate was determined by electrocardiographic monitoring. At baseline, systemic arterial pressure and heart rate were measured, and cineangiography of the left coronary artery was performed in orthogonal (right anterior oblique caudal and cranial) projections. Each subject then received topical, intranasal cocaine, 2 $\mathrm{mg} / \mathrm{kg}$. Fifteen minutes later, blood pressure and heart rate measurements and left coronary cineangiography were repeated, and a blond sample was ohtained for determination of cocaine concentration by gas chromatography. Immediately thereafter, patients were randomized to receive (1) intravenous saline (group I; $n=5$ ) or (2) intravenous verapamil, $10 \mathrm{mg}$ over $2 \mathrm{~min}$ utes (group $I I ; n=10$ ). Three minutes later, heart rate 